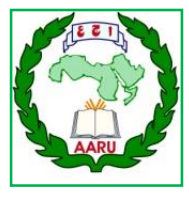

Arab Univ. J. Agric. Sci., Ain Shams Univ., Cairo, Egypt

29(2), 557-571, 2021

Website: http://ajs.journals.ekb.eg

DOI: 10.21608/ajs.2021.75553.1376

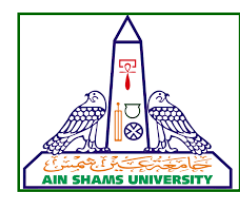

557

\title{
Impact of Microbial Synergism on Second Generation Production of Bioethanol from Fruit Peels Wastes
}

[38]

Sameh F Fahim
1- Agricultural Microbiology and Biotechnology, Botany Department, Faculty of Agriculture, Menoufia University, Postal Code 32516, Eastern Bank, Shebin El-Kom, Menoufia, Egypt.

2- Biochemistry department, Faculty of Agriculture, Menoufia University, Postal Code 32516, Mostafa Kamel St., Eastern Bank, Shebin El-Kom, Menoufia, Egypt

*Corresponding author: Kemam mahmoud@agr.menofia.edu.eg

Received 19 May, 2021

Accepted 12 June, 2021

calcium oxide increased the purity which leads finally to $97.5 w t \%$ of pure bioethanol. Thrust towards fossil fuels replacement with renewable clean fuels such as bioethanol by using fruit peels residuals which are considered renewable energy source may also help in $\mathrm{CO}_{2}$ mitigation.

Keywords: Fruit peels, Bioethanol, Fungi co-cultivation, Yeast co-fermentation

\section{Introduction}

The huge amounts of consumed fresh fruit encouraged the expansion use of its peels residues to improve their economic productivity competitiveness (Cutzu and Bardi 2017). Most of fruits after its consumption generates about $50 \%$ of their weight as un-eatable waste, its utilization to generate bioethanol from their huge effluents as substrates will indeed reduce the processing costs and environmental load for agro-wastes management (Hu et al 2011). While the most of global food waste are arises from fruits and vegetables residues, fruits peels are alone account about $37 \%$ of the total agricultural waste according to the statics of Food and Agriculture Organisation (Makkar 2013). Also, the major organic matter generated daily by farms, household's consumption and food 
processing manufacturers are fruits rinds and peels, these disposed organic materials that pose an environmental risk due to their high biological oxygen demand (BOD) (Ververis et al 2007). These fruit residues are of no commercial importance and mostly disposed of in municipal dumps by large quantities, which causes of serious organic pollution (Oberoi et al 2013). Among them, the major contents of fruits peels are cellulose and hemicellulose with significant amounts of lignin placed between them, these lignocellulosic are considered a great renewable raw material for competitive production of bioethanol in the open market (Makkar 2013). Unfortunately, peels cells are mainly composed from complex fibers, these fibers are covalently hemicelluloses coupled with lignin and linked by hydrogen bonds with cellulose (Chen and Fu 2016). The complex compound ties all the constituents of peels which is the principal barrier to their uses valorisation, therefore a process of pre-treatment is inevitable to separate hemicellulose and lignin from cellulose (Demirbas 2011). Many approaches have been developed to treat hemicelluloses and lignocelluloses biomass to separate their chemical components, in which bioethanol production is the major target (Lee et al 2014). Thus, the primarily chemical components that can be fermented to alcoholic component are simple sugars, the latter cannot get it without other treatment step named saccharification process, there is no substitute of the latter process for separating them from polysaccharides to make fermentation possible (Chen and Fu 2016). Due to lignin properties, it is become the main obstacle which influences the digestibility of the biomass. Therefore, the high resistant lignin crystalline structure could be lowering the biomass digestibility. Whereas the stimulation of lignin degradation would be stimulating its digestibility (Agbor et al 2011). Overall, the commercial production has not yet been implemented because of production cost elevation based on available pre-treatment technologies (Dien et al 2003). Even though dilute acid and hydrothermal pre-treatment are the most common and economic than the other pre-treatment methods, but some of these methods would be more harmful to the environment than others as the chemical free pre-treatment such as hydrolysing enzymes which is environmentally attractive solutions although it is still high cost (Rocha-Meneses et al 2019). Microbial enzymatic hydrolysis is more promising than any others chemical or physical hydrolysis since lower utility costs with highest productivity (Hu et al 2011). The commercially available enzymes mixtures are produced by Aspergillus species especially $A$. niger strains are the most commonly industrial fungus which produced a broad range of degrading exo-enzymes, such fungal enzymes are essential to convert complicated plant polymers into simple molecules that can be up-taken into their cells (Arya et al 2001). Also, the enzymatic treatment would also avoid initially physical or chemical treatments for the easily sugars recover without various inhibitions (Hu et al 2011). Many authors pointed that, during fungal natural life cycle most fungi live in mixed communities within symbiosis or competition particular biotope and may be colonized mainly by several Aspergilli species (Arya et al 2001, Hu et al 2011). Thus, the fungi co-cultivation may result more in more efficient enzyme mixtures for various applications than those result from monoculture (Arya et al 2001). The fungal cocultivations were previously described for efficient productivity of degrading enzymes, the ascomycete strains of $A$. niger and the basidiomycete white rot fungus Phanerochaete chrysosporium could improve the activity of cellulolytic and hemi-cellulosic enzymes and improve ligninolytic enzymes production (Verma and Madamwar 2002). Another side, the yeasts belonging to Saccharomyces genus is commonly used for alcoholic fermentation, especially the typical species of $S$. cerevisiae is ordinary considered the common fermentation species, it has the highest yield and ethanol tolerance (López-Malo et al 2013). In addition, the most of current theoretical for bioethanol production were by $S$. cerevisiae which aptitude to grow at low $\mathrm{pH}$ and elevated temperature, also its capable to grow in presence of inhibitors, the using of converted sugars by $S$. 


\section{Impact of Microbial Synergism on Second Generation Production of Bioethanol from Fruit Peels Wastes}

cerevisiae was far better from enzyme hydrolysate than that from other chemical treated fruit wastes (Gashaw 2014). Unfortunately, the ideal mould type which can be efficiently fermented both $\mathrm{C}_{5}$ and $\mathrm{C}_{6}$ sugars has not been yet isolated, nonetheless it cannot ferment the hemicellulose which are converted during pentoses fermentation into toxic furfural (Farias et al 2017). Up-to dated researchers have valorised the ability of ethanologens yeast strains for simultaneous cultivation with another strain with $S$. cerevisiae, this trend became widespread to be effective for fermenting both hexoses (glucose) and pentoses (xylose) sugars for high bioethanol yield which decreased the initial investment and maintenance costs (Yadav et al 2011). Occasionally, the yeast strain of Kluyveromyces marxianus is economically advantageous that can metabolize a wide variety of sugars via homo-ethanol pathway, although it requires a higher cells number than $S$. cerevisiae to produce comparable amounts of bioethanol (Widmer et al 2009). As microbial fermentation is an overpower process, special attention is required to control fermentation temperature, so the alcoholic yeast strains resistant to high temperatures are more favourable for bioethanol industry (Fahim 2017). Temperature is an essential parameter for the fermentation process, the ethanol production increases with increasing temperature, the temperatures that allow an optimal growth and better yield of bioethanol are generally range between $20^{\circ} \mathrm{C}$ and $35^{\circ} \mathrm{C}$ ( $\mathrm{Li}$ et al 2010). The theoretical maximum hydrous bioethanol formed after distillation process of fermentation broth was achievable no more than $95.5 \mathrm{wt}$ $\%$ ethanol and $4.5 \%$ water (Kumar et al 2010). However, the fuel consumption is increasing sharply despite the apparent lack of conventional fossil fuel supplies, only pure bioethanol can be used as a fuel or blended with gasohol as octane boosters ( $\mathrm{Li}$ et al 2010). The most important bioethanol proper burning benefits that air quality will improve by $\mathrm{CO}_{2}$ mitigation, bioethanol can also improve the octane number by replace with other additives in gasoline fuel, gasoline-bioethanol blend provides the highest braking power (Cutzu and Bardi 2017). Also, bioethanol fuel is sulphur free and totally biodegradable, that the incomplete oxidation pi-products are acetaldehyde and acetic acid which are less toxic by comparison with other alcohols (Sharma 2006). Although, the larger scale and world commercial production of biofuels mainly were mostly from essential oil, food, fodder crops at such a global scale would be another challenge for the availability of alternative feedstocks at that many scales (Makkar 2013). Therefore, the cost-effective means for producing bioethanol from four fruit peels (Banana, Orange, Mango and Watermelon), enzymes yielded from cofungal cultivation carried by Aspergillus niger and Phanerochaete chrysosporium, followed by co-fermentation of the saccharified sugars using yeast belong to Saccharomyces cerevisiae and Kluyveromyces marxianus which contributed for bioethanol production in $8 \mathrm{~L}$ lab-scale reactor, additional distillation process by adding drying agents increased the bioethanol final purity.

\section{Materials and Methods}

\subsection{Agricultural wastes preparation}

Four different fruits peels Musa acuminate (Banana), Mangifera indica (Mango), Citrus aurantium (Orange) and Citrullus lanatus (Watermelon) were collected. Minced samples oven dried at $70^{\circ} \mathrm{C}$ for $48 \mathrm{~h}$ and grind to be used later as source of fermentable sugars. Tissues samples were stored in airtight containers in the dark at room temperature until biochemical analysis. The dry weight (DW) was determined by oven dried of 5 grams of each fresh fruit peel at $105^{\circ} \mathrm{C}$ for not less than 2 hours or to mass constant, the $\mathrm{pH}$ was measured by using HI83141 Hanna instruments. Total proteins were measured as $\left(1 \mathrm{ABS}=1 \mathrm{mg} \cdot \mathrm{ml}^{-1}\right)$ by

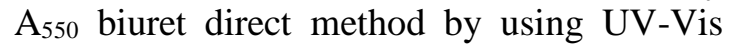
Spectro (Thermo Fisher Scientific ${ }^{\mathrm{TM}}$ ) (Bradford 1976). 


\subsection{Microbial strains and culture media}

The identified fungus and yeast strains used in this study were Aspergillus niger ATCC $^{\circledR}$ 64974TM, Phanerochaete chrysosporium ATCC $^{\circledR} 24725^{\mathrm{TM}}$, Kluyveromyces marxianus ATCC $^{\circledR} 36142^{\mathrm{TM}}$ and Saccharomyces cervisiae ATCC $^{\circledR} 9763^{\mathrm{TM}}$ brought from the national Mircen (Microbiological Resource Center, Ain Shams University). All fungal strains grown on malt extract agar (MEA, Difco) to obtain spores. To achieve the fungal behaviour in terms of mycelial interactions and growths rates on various culture media, fungi mixture cultivated on (MEA), potato dextrose agar (PDA, Difco) and Aspergillus complete medium (ACM, Difco) (De Vries et al 2004). This latest culture medium was chosen and supplemented with $5 \%$ wheat brain $(\mathrm{Wb})$ as the sole source of carbon for achievement of fungi behaviours. In the same order, the (ACM) liquid culture medium was chosen and supplemented with $5 \%$ powders of Banana peel (Bp), Watermelon peel (Wp), Orange peel (Op) and Mango peel (Mp), respectively as carbon substrate source for mixed enzymes production. On the other side, laboratory cultures of $S \mathrm{cer}$ visiae and $K$ marxianus strains were routinely maintained on sodium acetate ascospore agar (SAA, Himedia) for creating new generation by ascospores germination (McClary et al 1959). The regenerative strains were screened to use as bioethanol co-producers based on $(+20 \%$ glucose, xylose fermentative and alcohols tolerance). While the glucose peptone agar medium, (GPA, Difco) was used for examining the new yeasts spontaneous mutant selected from the ascospores sexual conjugation. The yeast strains were primarily examined for xylose utilisation, $\mathrm{CO}_{2}$ emission, ethanol tolerance and productivity using $2 \%$ glucose or/and xylose (1:1 mixture) supplemented peptone broth medium. The optical densities at $\mathrm{OD}_{600}$ were used as indicator of growths rates. While the medium used for ethanol production composed of (Yeast extract 2.5 g. $\mathrm{l}^{-1}$, $\left(\mathrm{NH}_{4}\right)_{2} \mathrm{SO}_{4} 2.5$ g. $l^{-1}, \mathrm{KH}_{2} \mathrm{PO}_{4} 1$ g. $l^{-1}$ and $\mathrm{MgSO}_{4}$ $0.5 \mathrm{~g} . \mathrm{l}^{-1}$ ) which later supplied by amounts of filtrated enzymatically produced sugars.

\subsection{Cultivation conditions and fermentation setup}

For fungi maintenance and spores inoculums preparation, spore production on MEA medium slants usually requires minimum $72 \mathrm{~h}$ of growth at $40^{\circ} \mathrm{C}$, spores (conidia) suspended in $5 \mathrm{ml}$ of sterile water and then filtrated through sterile glass wool to avoid presence of fungus mycelia. Spores concentration were determined by measuring the absorbance at 650 $\mathrm{nm}\left(\mathrm{ABS} 1 \mathrm{~cm}^{-1}=5 \times 10^{6}\right.$ spores.mll $\left.{ }^{-1}\right)$. Fungi co-enumerated by inoculating $1 \mathrm{ml}$ of diluted spores suspension $\left(5 \times 10^{5}\right.$ spores. $\left.\mathrm{ml}^{-1}\right)$ with a distance of $3.5 \mathrm{~cm}$ or by inoculate the spores mixture in the centre or over the Petri dishes whole surface. For all liquid cultures, fungi grown on $250 \mathrm{ml}$ shaking Erlenmeyer flasks with $40 \%$ filling volume, $250 \mathrm{rpm}$ agitation rate and $0.0163 \mathrm{~S}^{-1}$ coefficient volumetric oxygen transfer rate $\left(k_{L} a\right)$ (Fahim 2017). ACM medium supplemented with $5 \%$ of various peels carbon sources, the culture medium inoculated by $5 \times 10^{6}$ spores. $\mathrm{ml}^{-1}$ and incubated at 40 ${ }^{\circ} \mathrm{C}$ for $96 \mathrm{~h}$. On other side, 8 litre lab-scale fermentor (New Brunswick Scientific MicroFerm MF-114, USA) was used for submerged fermentation (62.5\% filling volume, $250 \mathrm{rpm}$ agitation rate and $k_{L} a 0.0165 \mathrm{~S}^{-1}$ ) as followed by (Fahim 2017). For enzymes production, ACM medium supplemented with $5 \%$ of wheat brain and inoculated by $5 \times 10^{6}$ spores. $\mathrm{ml}^{-1}$ of mixed fungi, then incubated aerobically at $40^{\circ} \mathrm{C}$ for $96 \mathrm{~h}$. Culture samples harvested and centrifuged at $10.000 \mathrm{rpm}$ for $10 \mathrm{~min}$, supernatant was then filtrated through $0.045 \mu \mathrm{m}$ nitrocellulose microbiological membrane filter, the filtrate aliquots culture sample used as degrading enzymes source or stored at $-20^{\circ} \mathrm{C}$ no more than 1 week. For bioethanol production, the culture medium supplemented with $5 \%$ powders of (Bp, Mp, Wp and Op) respectively as carbon sources replacements, the culture medium was initially inoculated by $0.5 \mathrm{OD}_{600} S$. cerevisiae, $K$. marxianus or mixed inoculums at $35^{\circ} \mathrm{C}$ under non aerated condition for $24 \mathrm{~h}$ of fermentation period. 


\section{Impact of Microbial Synergism on Second Generation Production of Bioethanol from Fruit Peels Wastes}

\subsection{Sugars extraction and oligosaccharides fractionation}

The purpose of sugars purification before the oligo-saccharides fractionation was to avoid influence of free sugars on the pectin, hemicellulose, and cellulose determinations. The ethanol extraction method was applied to extract the soluble sugars on each peels tissue sample, five replicates of $(50 \mathrm{mg})$ extracted with $5 \mathrm{ml}$ of ethanol $80 \%$ and repeated three times, by boiling at $95^{\circ} \mathrm{C}$ for $10 \mathrm{~min}$ in screw cape glass tubes followed by 2500 rpm centrifugation for $5 \mathrm{~min}$, the collected supernatants combined for sugar analysis. While the rest of the pellets in the tubes were used for starch determination or stored wet at $-20^{\circ} \mathrm{C}$ to analyze the starch later with the hydrolyzed extracted sugars from the oligosaccharides (Cutzu and Bardi 2017). The fruit peels oligosaccharides fractionation process is conducted by the patent application number 420890 published by Szymańska-Chargot and co-workers. 50 grams of minced fruits peels tissues boiled with 300 $\mathrm{ml}$ distilled water in $1 \mathrm{~L}$ glass piker for $10 \mathrm{~min}$ and filtrated to remove simple soluble polysaccharides and phenolic compounds from peels in the aqueous solution. For separating the pectin polysaccharides components, the residual tissues treated by $300 \mathrm{ml}$ of hydrochloric acid $(1 \mathrm{M})$ and magnetically stirred at $85^{\circ} \mathrm{C}$ for 30 $\mathrm{min}$, and then filtered to collect the pectic polysaccharides compounds in the aqueous solution and the rest of residual bulk was used to extract the hemicellulose polysaccharides compounds by adding $300 \mathrm{ml}$ of sodium hydroxide $(1 \mathrm{M})$. This mixture was magnetically stirred at $85^{\circ} \mathrm{C}$ for $30 \mathrm{~min}$, and then filtered to collect the hemicelluloses components in the aqueous solution and the rest residual bulk transferred to new glass piker to the next step. Afterwards, the lignin compounds removed by adding $300 \mathrm{ml}$ of sodium hypochlorite (2\%) and magnetically stirred at $95^{\circ} \mathrm{C}$ for $60 \mathrm{~min}$ subsequently by transfer the colloidal solution as lignin matter. The end step conducted by collecting the cellulose matter from the rest bulk amount and washed three times by deionized water until the alkaline traces removed (Ziemiński and Kowalska-Wentel 2017).

\subsection{Reduced sugars and oligosaccharides quantifications}

Considering the potential use of the end isolation step of cellulose supernatant, the quantification of pectin, hemicelluloses and cellulose contents in fruits peels carried out. The pectic fractions contents performed with colorimetric calibration method of galacturonic acid which transformed into furfural derivatives by reacting with carbazole acid in acidic phase (Orozco et al 2014). The collected pectic residuals rinsed and placed into $200 \mu 1$ of deionized water followed by gradually addition of $3 \mathrm{ml}\left(\mathrm{H}_{2} \mathrm{SO}_{4}\right)_{\text {conc }}$ and $100 \mu \mathrm{l}$ carbazole reagent $(0.1 \% \mathrm{w} / \mathrm{v}$ ethanol). The mixer kept for $60 \mathrm{~min}$ in the dark at $60^{\circ} \mathrm{C}$ and cooling through water bath (caution of exothermic reaction), then after development of pink-red colour, the absorption read at wavelength $530 \mathrm{~nm}$ were done against the standards curves obtained from galacturonic acid. However, the acid hydrolyzed GFX monomer sugars mixture (glucose, fructose, and xylose) in peels tissue extracts from the oligosaccharides such as hemicelluloses determined by the phenol-sulfuric acid method (Dubois et al 1956). The reaction of $1 \mathrm{ml}$ phenol $2 \%$ solution with $0.5 \mathrm{ml}$ of examined sugars solutions, the standard sugars were made by increments concentrations from 50 to $100 \mu \mathrm{g} \cdot \mathrm{ml}^{-1}$ of the most common sugar mixture with percentage (1:1:1 GFX mixture) or the individual glucose and xylose solutions, respectively. This reaction followed by the quickly and gradually addition of $2.5 \mathrm{ml}$ $\left(\mathrm{H}_{2} \mathrm{SO}_{4}\right)_{\text {conc }}$ and kept for 10 min in the dark at $20^{\circ} \mathrm{C}$ in cooling water bath (caution of exothermic reaction), subsequently after development of yellow brown colour, the absorption read at wavelength $490 \mathrm{~nm}$ were done against the standards curves obtained from individual sugars or the GFX mixture for total reduced sugars assay. 


\subsection{Degrading enzymes assays and SDS- PAGE profiles}

For the cellulase enzyme activity, the method of filter paper (Whatman no.1) activity was applied (Camassola and Dillon 2012). $\beta$ glucosidase activity determined by using 5 carboxy methyl cellulose $\left(10{\mathrm{~g} . \mathrm{l}^{-1}}^{-1}\right)$ as carbon replacement source in ACM media (Saddler and Mes-Hartree 1984). Xylanase activity determined under the same conditions by supplying ACM media with $\left(1 \mathrm{ml} . \mathrm{l}^{-1}\right)$ extracted wheat bran solution (Saddler and Mes-Hartree 1984). While the liberated reduced sugars from cellulose as (glucose) and (xylose) from hemicellulose in the latest reaction mixtures measured by the phenol-sulfuric acid methods which used later to determine the extracted monomers sugars from the oligosaccharides, each 1 $\mu \mathrm{mol} . \mathrm{min}^{-1} \cdot \mathrm{ml}^{-1}$ of released glucose or xylose expressed as one unite of cellulase, $\beta$-glucosidase and xylanase enzymes respectively under specified experimental conditions. Protein precipitation carried out with salting technique by adding ammonium sulphate slowly to the cell-free culture (at $75 \%$ saturation) with magnetically stirring to complete protein precipitation. The precipitate collected by centrifugation at $10.000 \times \mathrm{g}$ for $20 \mathrm{~min}$ and then dissolved in $50 \mathrm{mmol}$ phosphate buffer ( $\mathrm{pH} 8.0)$, dialysed and stored (Switzer et al 1979). For molecular weight determination, the sodium dodecyl sulphate polyacrylamide gel electrophoresis (SDS-PAGE) profiles for extra-cellular degrading enzymes were preformed, the gel made of (10\%) polyacrylamide and 5\% stacking gels. After electrophoresis, the gels stained with Coomassie brilliant Blue R-250 staining and overnight de-stained by $45 \%$ methanol and $10 \%$ acetic acid (Switzer et al 1979).

\subsection{Enzymatic hydrolysis and bioethanol production processes}

The filtrate culture showing activities of cellulases and xylanases was used for enzymatic hydrolysis processes, the bioreactor supplied with $250 \mathrm{~g}$ of fruits peels within $4975 \mathrm{ml}$ of adjusted pH 5.5 filtrate culture media (buffered by $0.1 \mathrm{M}$ sodium acetate solution), the total hybridisation volume conducted at $50^{\circ} \mathrm{C}$ for $72 \mathrm{~h}$. By progressing the enzymatic hydrolysis process, collected samples centrifuged at $10.000 \mathrm{rpm}$ for $10 \mathrm{~min}$, supernatant was then filtrated through $0.045 \mu \mathrm{m}$ nitrocellulose microbiological membrane filter, the filtrate aliquots samples used as sugars sources or stored at $5^{\circ} \mathrm{C}$ no more than 1 month. Samples of the used (Bp, Mp, Wp and Op) substrates chemically analysed, the total of each substrate suspensions used to supplement the production bioethanol medium, respectively as carbon source replacement. 5 litre of culture medium was initially inoculated by $0.5 \mathrm{OD}_{600} \mathrm{~S}$. cervisiae, $K$. marxianus or mixed inoculums and mechanically stirred by $150 \mathrm{rpm}$ under non aerated condition at $35^{\circ} \mathrm{C}$ for $24 \mathrm{~h}$ of fermentation period (initial sugars concentration determined). After alcoholic fermentation process, the bioethanol yield determined spectrophotometrically according to the modified chromic acid method developed by (Gupte and Madamwar 1997), $1 \mathrm{ml}$ of fermentation culture broth diluted to $5 \mathrm{ml}$ by distilled water and 5 $\mathrm{ml}$ of chromic acid reagent added $(34 \mathrm{~g}$ $\mathrm{K}_{2} \mathrm{Cr}_{2} \mathrm{O}_{7}$ within $325 \mathrm{ml} \mathrm{H}_{2} \mathrm{SO}_{4 \text { conc }}$ and the total volume adjusted to $1000 \mathrm{ml}$ with distilled water). The screw cap tubes heated in a water bath at $60^{\circ} \mathrm{C}$ for $20 \mathrm{~min}$. the absorbance of alcohols determined at $600 \mathrm{~nm}$ by using absolute ethanol standard curve, after that $\mathrm{CO}_{2}$ levels can be calculated. For collecting bioethanol from culture broth, the azeotropic distillation process applied at $78.2^{\circ} \mathrm{C}$ and coupling with addition of $0.5 \mathrm{~g} . \mathrm{l}^{-1}$ calcium oxide as drying agent during distillation process ( $\mathrm{Li}$ et al 2010).

\section{Results and Discussion}

\subsection{Fungi co-cultivation}

To achieve whether the ability of two fungi for growth together in the same culture and their behaviours, several pour plates inoculated by both fungi as described in the enumeration conditions. Different radial extension rates monitored for the two fungi on MEA 


\section{Impact of Microbial Synergism on Second Generation Production of Bioethanol from Fruit Peels Wastes}

solid culture medium. A. niger has the fastest growth fungus, while $P$. chrysosporium has particular moderate growth (Fig 1-A). The tested fungi have been the ability to grew on all used types of culture media in this investigation, in this order the (ACM) culture resulted the better and fasted culture growth. This liquid culture was chosen and supplemented with $5 \%$ wheat brain as the sole source of carbon for fungi enumeration and enzymes production. Since an earlier study reported that on the wheat brain carbon source has stimulation effect on a broad range of hydrolytic enzymes secretion by several Aspergillus types (Meijer et al 2011). The co-cultivation which primarily performed on the separated inoculums and spores mixture poured plates showed the lifestyle behaviour of two fungi. The separated inoculants a distance away from each other formed colonies with complete edges when they met without any significant forced invasion (non-antagonistic effect) for the other fungus occupied plate area, but $P$. chrysosporium could grow around and within the other fungus (Fig 1-B). Interestingly, the spores mixed inoculation in the same spot, there is no sectors containing either fungus could be observed on the plates (Fig 1-C) generally, A. niger has colonies with a black colour, while $P$. chrysosporium characterized by its white colonies. On other side, no fungus mycelia appeared during the first $20 \mathrm{~h}$ of cultivation, after $40 \mathrm{~h}$ the hypha of both fungi starting to formation, then quickly spread by $P$. Chrysosporium more than $A$. niger which occupied less area in the presence of the other fungus which covered whole the plate with a white hypha and grown within the other fungus to reach outside its colony. These evidences similar with those experiments which performed by combinations of some fungi genera such as A. niger, A. oryaza, $P$. chrysosporium and Magnaporthe grisea, in all these genera combinations no one of these species showed to out contrary of other fungus genus (Rocha-Meneses et al 2019).

\subsection{Yeasts co-fermentation}

Approximately (34) of S. cervisiae and (42) $K$. marxianus generated yeasts isolates screened for cultivations tests, the highest $\mathrm{CO}_{2}$ emission strains during glucose or/and xylose sugars fermentations selected. The alcohol tolerance and the ability to mono sugar or co-carbon sugar utilization conducted for the selected two strains type, data presented in (Table 1). S. cervisiae selected strain showed the highest indicators levels of sugar utilization rate and gas emission by $1.12 \mathrm{~g} \cdot \mathrm{l}^{-1} \cdot h^{-1}$ and 0.2 mol. $^{-1}$ respectively when glucose was the carbon source, despite of it cannot be utilize xylose sugar as carbon source (López-Malo et al 2013). While selected $K$. marxianus strain showed double uses of the glucose and xylose or sugars mixture with moderated levels by $0.68 \mathrm{~g} . \mathrm{l}^{-1} . \mathrm{h}^{-1}$ and $0.12 \mathrm{~mol} . \mathrm{l}^{-1} \mathrm{CO}_{2}$ emission. It worth to note that, the yeast co-culture showed high levels of glucose sugar utilization rate by $1.26 \mathrm{~g} . \mathrm{l}^{-1} \cdot \mathrm{h}^{-1}$ and $0.17 \mathrm{mol.} \mathrm{l}^{-1} \mathrm{CO}_{2}$ emission. Also, they recorded good levels of mixed sugar consummation by $0.83 \mathrm{~g} \cdot \mathrm{l}^{-1} \cdot \mathrm{h}^{-1}$ and $0.16 \mathrm{~mol} . \mathrm{l}^{-}$ ${ }^{I}$ gas emission. Although, the possibility of xylose sugar fermentation recorded by selected strain of $K$. marxianus in single or co-culture condition, which it showed lowest level of sugar consummation and $\mathrm{CO}_{2}$ emission by 0.55 g. $l^{-1} . h^{-1}$ and 0.12 mol. $l^{-1}$, respectively. On other side, it is clear from (Fig. 2), that S. cervisiae have a potential for growth and make a high ethanol yield only from glucose by 9.23 g. $l^{-1}$ at no more than $18 \mathrm{~h}$. While $K$. marxianus showed moderated ethanol yield by 4.91, 5.58 and $6.17 \mathrm{~g} . \mathrm{l}^{-1}$ from xylose, mixed sugars, and glucose respectively, with more long fermentation period than the other yeast strain. By tracking the co-fermentation of the two strain showed a good ethanol yield by $7.83 \mathrm{~g} . \mathrm{l}^{-1}$ from glucose at no more than $16 \mathrm{~h}$ and $7.83{\mathrm{~g} . \mathrm{l}^{-1}}^{-1}$ from mixed sugars during $24 \mathrm{~h}$. Also, co-fermentation showed moderated values of ethanol

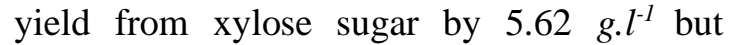



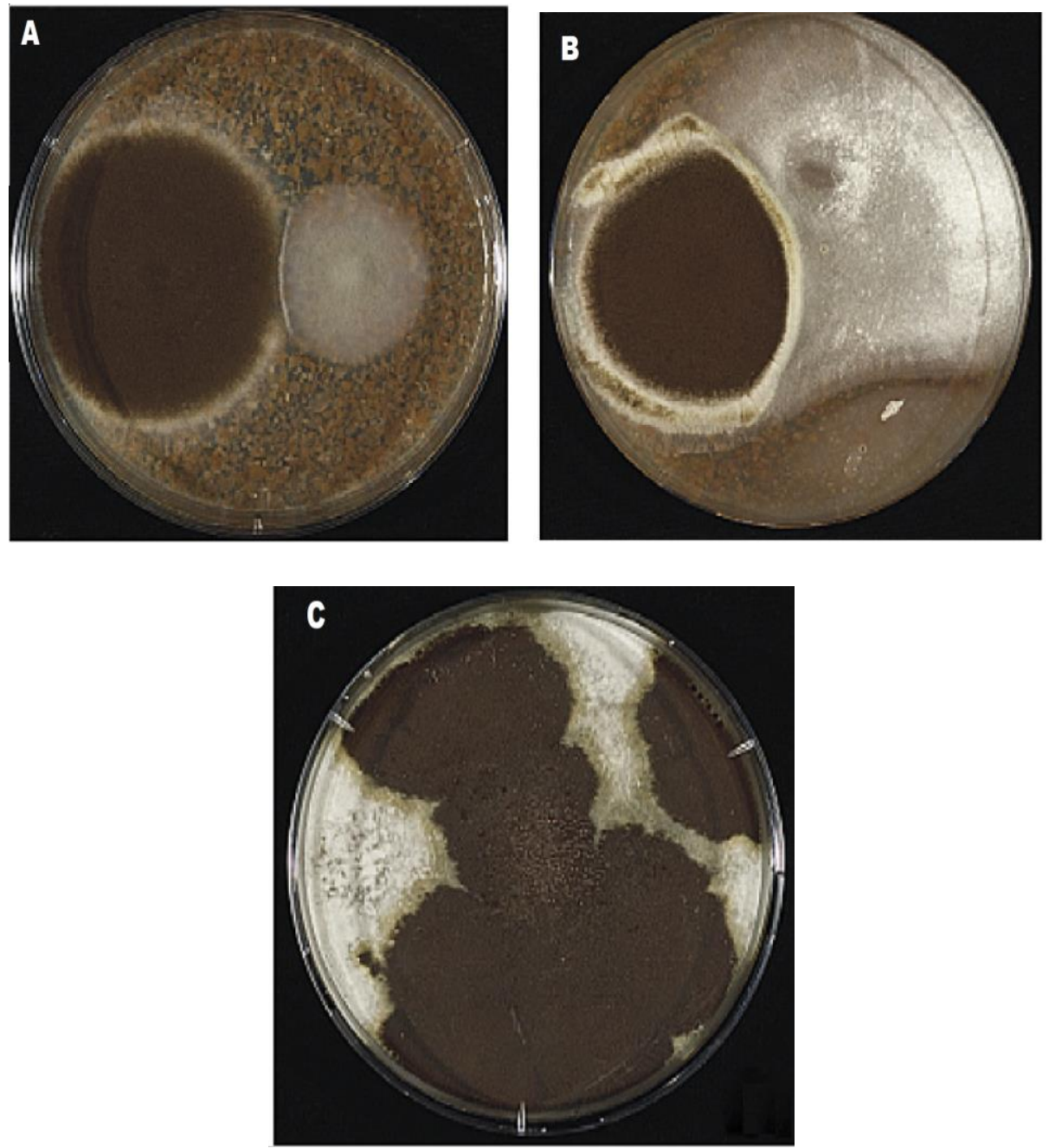

Fig 1. Co-cultivation of $A$. niger and $P$. chrysosporium fungi on solid $\mathrm{ACM}+5 \% \mathrm{~Wb}$ by inoculating them separately (A) and after complete growth (B) or as a spore mixture (C)

Table 1. The bioethanol productivity indicators of the selected yeast strains and its co-fermentation

\begin{tabular}{|c|c|c|c|c|c|c|c|c|c|}
\hline \multirow{2}{*}{ Yeast strains } & \multicolumn{3}{|c|}{$\begin{array}{c}\mathrm{CO}_{2} \text { emission } \\
\text { mol.l } l^{-1}\end{array}$} & \multicolumn{3}{|c|}{$\begin{array}{c}\text { Sugars utilization rate } \\
g . l^{-1} \cdot h^{-1}\end{array}$} & \multicolumn{3}{|c|}{$\begin{array}{l}\text { Max bioethanol production } \\
\text { g. } l^{-1}\end{array}$} \\
\hline & Glucose & Xyl & $\begin{array}{l}\text { GX. } \\
\text { Mix }\end{array}$ & Glucose & Xylose & $\begin{array}{l}\text { GX. } \\
\text { Mix }\end{array}$ & Glucose & Xylose & GX. Mix \\
\hline S. cervisiae & $\begin{aligned} & 0.2 \\
& \pm 0.06 \\
&\end{aligned}$ & $\begin{array}{c}0.0 \\
\pm 0.0 \\
\end{array}$ & $\begin{array}{c}0.09 \\
\pm 0.04 * \\
\end{array}$ & $\begin{array}{r}1.12 \\
\pm 0.05 \\
\end{array}$ & $\begin{array}{c}0.0 \\
\pm 0.0 \\
\end{array}$ & $\begin{aligned} & 1.43 \\
& \pm 0.08 * \\
&\end{aligned}$ & $\begin{array}{r}9.2 \\
\pm 0 \\
\end{array}$ & $\begin{array}{c}0.0 \\
\pm 0.0\end{array}$ & $\begin{aligned} & 4.21 \\
& \pm 0.03 * \\
&\end{aligned}$ \\
\hline K. marxianus & $\begin{array}{c}0.14 \\
\pm 0.04 \\
\end{array}$ & $\begin{array}{c}0.11 \\
\pm 0.03 \\
\end{array}$ & $\begin{array}{c}0.12 \\
\pm 0.08 \\
\end{array}$ & $\begin{array}{c}0.79 \\
\pm 0.07 \\
\end{array}$ & $\begin{array}{c}0.57 \\
\pm 0.05 \\
\end{array}$ & \begin{tabular}{|c|}
0.68 \\
\pm 0.06 \\
\end{tabular} & $\begin{array}{c}6.17 \\
\pm 0.08 \\
\end{array}$ & $\begin{array}{c}4.91 \\
\pm 0.06 \\
\end{array}$ & $\begin{array}{c}5.58 \\
\pm 0.06 \\
\end{array}$ \\
\hline $\begin{array}{l}\text { Co-fermenta- } \\
\text { tion }\end{array}$ & $\begin{array}{l}0.17 \pm \\
0.05\end{array}$ & $\begin{array}{c}0.12 \pm \\
0.07\end{array}$ & $\begin{array}{c}0.16 \\
\pm 0.03\end{array}$ & $\begin{array}{r}1.26 \\
\pm 0.04\end{array}$ & $\begin{array}{c}0.55 \\
\pm 0.03\end{array}$ & $\begin{array}{l}0.83 \\
\pm 0.5\end{array}$ & $\begin{aligned} & 7.83 \\
\pm & 0.07\end{aligned}$ & $\begin{array}{r}5.62 \\
\pm 0.04\end{array}$ & $\begin{aligned} & 7.16 \\
\pm & 0.04\end{aligned}$ \\
\hline
\end{tabular}

The values are mean of three replicates \pm standard deviation.

* Values based on glucose sugar amounts only. 
fermentation period rich to more than $36 \mathrm{~h}$ by comparing the other single culture xylose fermentation. The previous data strongly referring to the co-fermentation importance by saving fermentation time and increasing the productivity, especially in the presence of $\mathrm{xy}$ lose sugar which are necessarily available in quantities within treated agro-wastes peels, these results matched with Widmer et al (2009).

\subsection{Fruit peels composition}

The primarily results of biochemical analyses for four different fruits peels examined are presented in (Table 2). The percentages on dry weight base of total proteins, starch, pectin, lignin, cellulose, and hemicellulose contents investigated, the mango peel showed the highest levels of starch, pectin, hemicellulose, and lignocelluloses components by $13.56 \%$, $11.89 \%, 14.51 \%$ and $51,48 \%$ respectively with highest level of lignin content by $17.25 \%$ and lowest level of total proteins by $3.89 \%$ (Berardini et al 2005). Also, the peel of banana showed high levels of starch, hemicellulose, and lignocelluloses components by $13.27 \%$, $12.93 \%$ and $38,14 \%$ respectively with the lowest level of lignin contents by $4.82 \%$, the proteins and pectin contents were in the moderated levels by $5.12 \%$ and $11.21 \%$, respectively ( $\mathrm{Li}$ et al 2010). While the orange peel showed the lowest levels of starch, hemicellulose, and lignocelluloses components by $3.22 \%, 9.27 \%$ and $30,76 \%$ respectively with $6.53 \%$ of lignin content, but the pectin content recorded the highest level by $16.45 \%$, the proteins levels were moderate by $5.23 \%$, which close to the report published by (AravantinosZafiris et al 1994). Citrus peels had somewhat lower hemicellulose and lignocellulose content as well. In the same order, the watermelon peel showed the highest level of total proteins by $8.84 \%$. Pectin, hemicellulose and lignocellulose contents were in moderate levels by $11.34 \%, 11.45 \%$ and $33.84 \%$ respectively with $9.87 \%$ and $11.34 \%$ of lignin and pectin contents, respectively. These results match with the reports of (Fish et al 2009, Li et al 2010) that banana and mango peels could be a rich, worthless cost source of dietary fibres, composed mainly of hemicellulose and lignocellulose polysaccharides (Berardini et al 2005, Li et al 2010). Considering these results, the peels of banana and mango seems to be good alternative of carbon sources suitable for conversion of bioethanol, this preference is due to the respected hexose as well as pentose sugars converted from the good levels of starch, cellulose, and hemicellulose respectively, in addition the ability of tested fungi for reducing the relatively amounts of lignin during the pre-treatment processes and fermentation process, while this view is supported by Ververis et al (2007).

\subsection{The co-culture motivation of degrading enzymes}

The better set of oligosaccharides degrading enzymes of each fungus specie conducted for achievement the optimum condition of submerged fermentation at the presence of other fungus. The fungi co-cultivation affect investigated by influence the oligosaccharides reduction amounts by degrading exo-enzymes, the selected cultivation conditions were also achieved during fungal species grown together on ACM culture media supplied with wheat bran and compared with the same conditions on single fungus culture, the data presented in (Table 3) illustrated the activities of three oligosaccharide-active enzymes cellulase, $\beta$-glucosidase and xylanase enzymes as they previously been remarked to be produced by each fungus strains. Overall, the co-cultivation resulted an increasing in exo-enzymes activities by 5.9, 8.7 and $81.4 \mathrm{nmol}^{\mathrm{min}}{ }^{-1} . \mathrm{ml}^{-1}$ for $\beta$-glucosidase, cellulase, and xylanase, respectively. Although, A. niger showed high enzymes activities compared with $P$. chrysosporium, but the activities of co-cultivation are still higher than to each single fungus culture. These positive co-operation effect between industrial 
Table 2. Biochemical analyses of examined fruit peels wastes based on dry weight percentage (\% w/w).

\begin{tabular}{|l|c|c|c|c|c|c|}
\hline \multicolumn{1}{c|}{$\begin{array}{c}\text { fruit peels } \\
\text { waste }\end{array}$} & \multirow{2}{*}{ Protein } & \multirow{2}{*}{ Starch } & \multirow{2}{*}{ Pectin } & \multicolumn{2}{c|}{ Lignocellulose } & \multirow{2}{*}{ Hemi-cellulose } \\
\cline { 5 - 7 } & & & & Lignin & Cellulose & \\
\hline Banana peel & $5.12 \pm 0.6$ & $13.27 \pm 0.3$ & $11.21 \pm 0.5$ & $4.82 \pm 0.6$ & $33.32 \pm 0.3$ & $12.93 \pm 0.4$ \\
\hline Mango peel & $3.89 \pm 0.3$ & $13.56 \pm 0.7$ & $11.89 \pm 0.2$ & $17.25 \pm 0.2$ & $34.23 \pm 0.5$ & $14.51 \pm 0.9$ \\
\hline Watermelon peel & $8.84 \pm 0.5$ & $4.36 \pm 0.6$ & $11.34 \pm 0.3$ & $9.87 \pm 0.4$ & $26.71 \pm 0.6$ & $11.45 \pm 0.2$ \\
\hline Orange peel & $5.23 \pm 0.9$ & $3.22 \pm 0.2$ & $16.45 \pm 0.6$ & $6.53 \pm 0.7$ & $24.23 \pm 0.4$ & $9.27 \pm 0.7$ \\
\hline
\end{tabular}

The values are mean of three replicates \pm standard deviation.
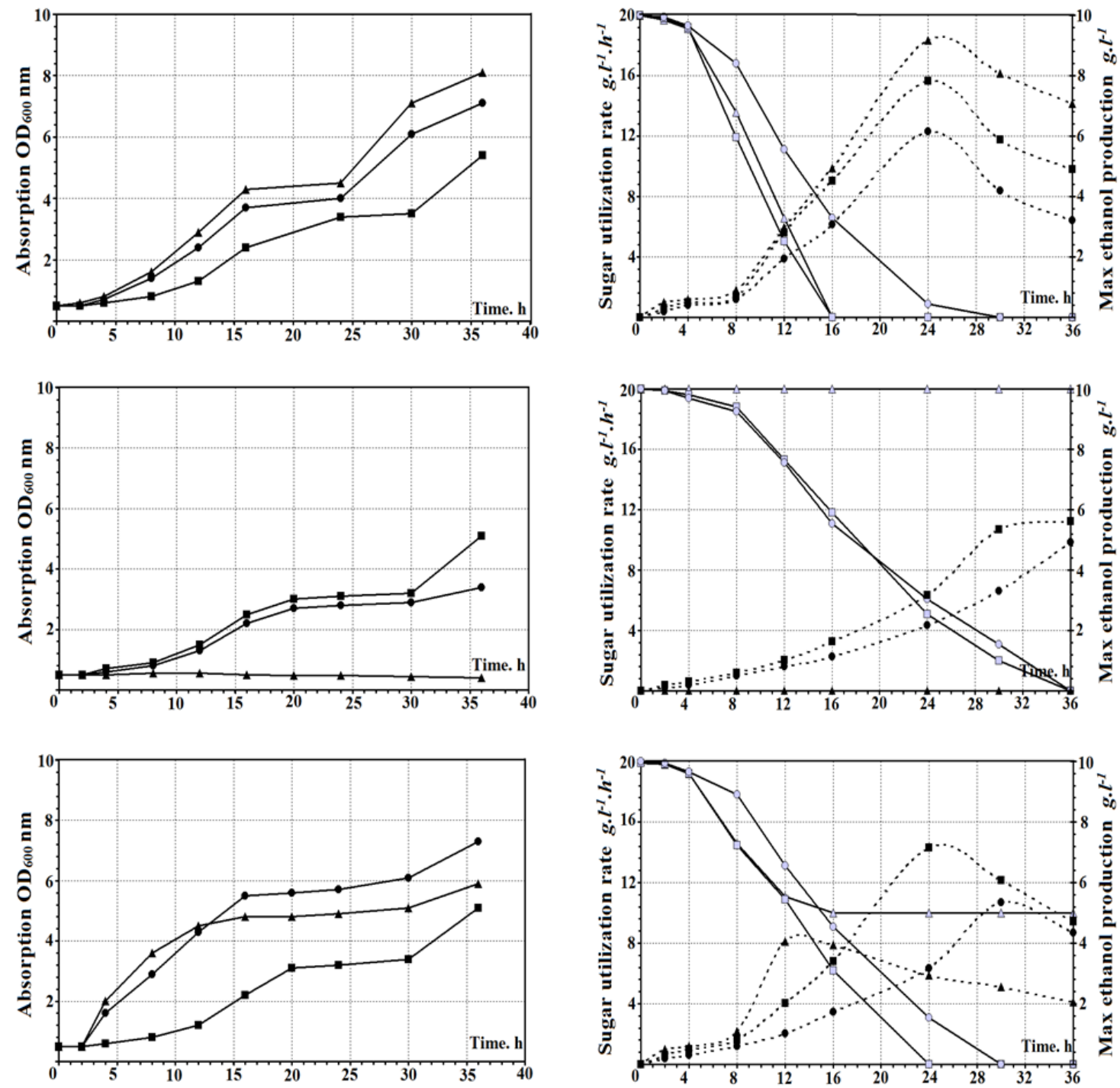

Fig 2. The bioethanol productivity indicators of the selected yeast strains and its co-fermentation of glucose, xylose, and sugars mixture respectively ( $\boldsymbol{\Delta}$ S. cervisiae $\bullet$ K. marxianus $\boldsymbol{\square}$ Co-fermentation) 


\section{Impact of Microbial Synergism on Second Generation Production of Bioethanol from Fruit Peels Wastes}

Table 3. Total secreted protein and exo-enzymes activities of A. niger, P. chrysosporium and its co-cultivation

\begin{tabular}{|c|c|c|c|c|}
\hline \multirow{2}{*}{ Fungi strains } & \multirow{2}{*}{$\begin{array}{c}\text { Total proteins } \\
\left(m g . m l^{-1}\right)\end{array}$} & \multicolumn{3}{|c|}{ Exo-Enzyme activities $\left(\right.$ nmol.min $\left.{ }^{-1} \cdot m^{-1}\right)$} \\
\hline & & Cellulase & $\beta$-glucosidase & Xylanase \\
\hline A. niger & $0.59 \pm 0.04$ & $7.9 \pm 0.18$ & $4.2 \pm 0.12$ & $72.8 \pm 0.24$ \\
\hline P. chrysosporium & $0.42 \pm 0.02$ & $6.2 \pm 0.15$ & $3.8 \pm 0.16$ & $5.3 \pm 0.26$ \\
\hline Co-cultivation & $0.65 \pm 0.03$ & $8.7 \pm 0.17$ & $5.9 \pm 0.17$ & $81.4 \pm 0.25$ \\
\hline
\end{tabular}

The values are mean of three replicates \pm standard deviation.

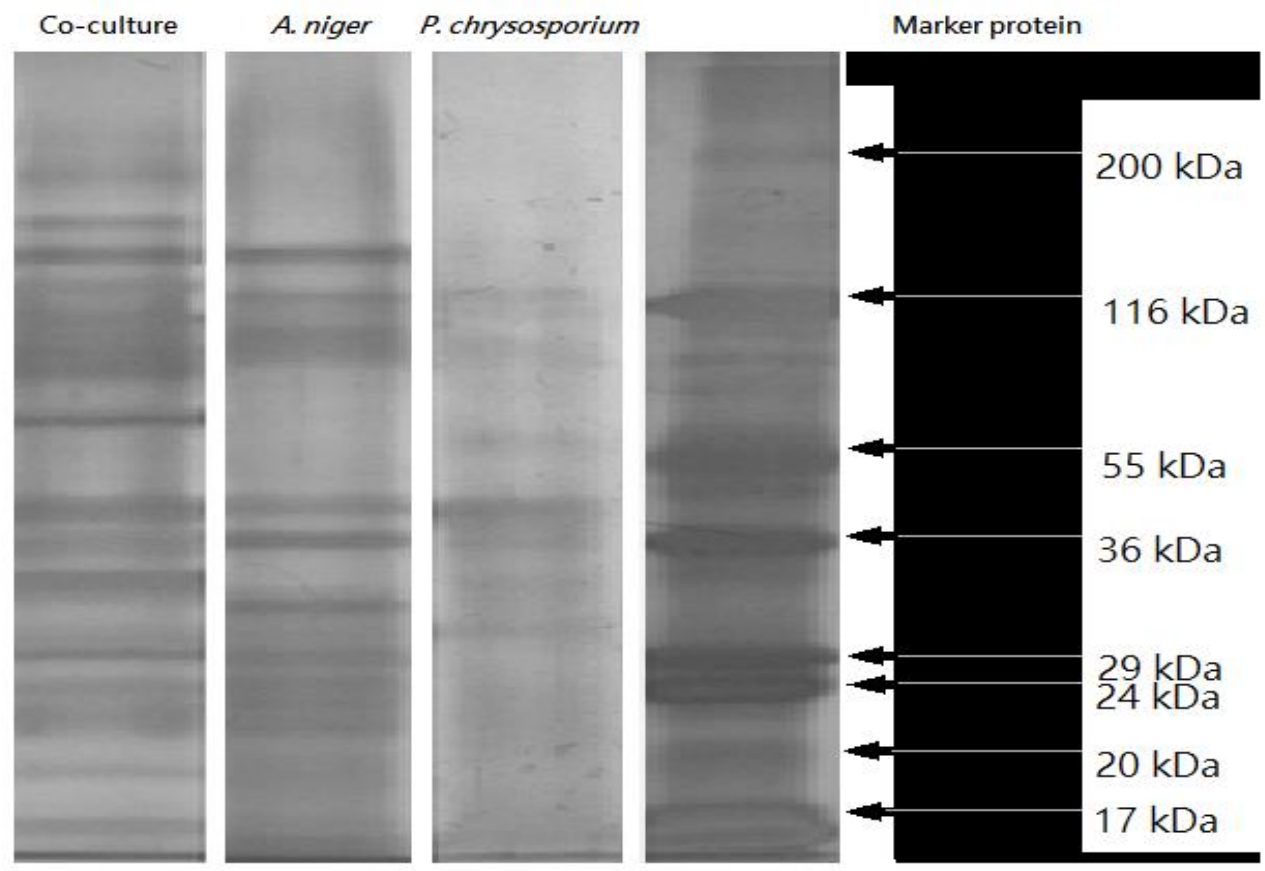

Fig 3. The SDS-PAGE protein profile of A. niger, $P$. chrysosporium and its co-cultivation

ascomycete $A$. niger and the wood rot $P$. chrysosporium basidiomycete fungus has been previously recorded by (Meijer et al 2011). The total secreted proteins in co-culture media $\left(0.65 \mathrm{mg} . \mathrm{ml}^{-1}\right)$ were also stronger than those resulted by individual culture. The fungi mixed culture does not result a big difference in secreted proteins amounts, but it triggered the stimulation of the specific enzymes. The importance value of the ligininase and hemicellulase enzymes in ameliorate the degrading of lignocellulosic fibers is by observing its synergistic actions along with enzymes of cellulases by increasing swelling and porosity of fibers and then facilitating its accessibility within it (Hu et al 2011). Also, the mode of action of the ligninase enzyme can formed fragile notches with continuous fissures in the fibers surfaces, while cellulases enzymes complex can begin from these patches, however the enzymes randomly function in synergism harmony (Greene et al 2015). Even though, the co-cultivations enzymes activities were approximately averaging of the two single cultures, but with consecration that only half spores inoculums from every fungus species used by comparing with the mono-cultivations which indicate to the overall activities of fungal co-cultivation and it 
can result in specific up-regulation, similar results were recorded for the same fungi strains by (Martinez et al 2004). On the other side, the SDS-PAGE profiles conducted for all culture type (Fig 3). Although, the figure illustrated the proteins profile of $A$. niger appeared to similar with the combined fungi proteins, but only fungi combined proteins profile contained proteins not observed in the individual fungus culture. These further proteins are undoubtedly related to the others degrading pectinase and ligninase enzymes, this case was also reported by $\mathrm{Hu}$, Martinez, and they co-workers, that an increase of laccase activity was observed for $A$. niger and $P$. chrysosporium co-culture (Martinez et al 2004). The proteomics studies on the cellulase enzyme have been further confirmed that, several extracellular fungal proteins observed due to the increasing on their synergistic action which were resulted from the release of cell separating exo-enzymes of, carboxymethyl cellulase, cellulase, xylanase, pectinase and other enzymes. Therefore, the hole hydrolase enzyme can be used to design a mixture of enzymes.

\subsection{Saccharification and bioethanol produc- tion}

The process of enzymatic degradation has been followed for achieved the effectually oligosaccharides hydrolyze into fermentable sugars (Table 4), the saccharified sugars yields and bioethanol production varied among the type of supplemented peels into production medium. Also, the bioethanol produced depended on the type of inoculated yeast strain. The mango and banana peels showed the highest saccharification of pentose and hexose sugars, the total released fermentable sugars

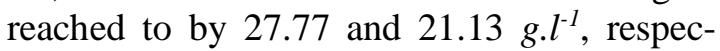
tively. In case of watermelon peels, the released fermentable sugars found to be at moderated level by $19.56 \mathrm{~g}^{-1}$, while orange peels produced $15.97 \mathrm{~g} . \mathrm{l}^{-1}$ at the lowest level of total fermentable sugars. Therefore, the bioethanol yield produced by single $S$. cervisiae fermentation was the best by $9.19,6.07,5.62$ and 4.45 g. $l^{-1}$ from saccharified peels of banana, watermelon, mango, and orange, respectively. As expected, the co-fermentation showed an increasing in bioethanol productivity by more than $18 \%$ as average percentage for all saccharified fruits peels. The maximum bioethanol productivity obtained from saccharified banana peels by $10.74 \mathrm{~g} . \mathrm{l}^{-1}$. Although, the mango peels founded to composite a good yield of oligosaccharides which they converted into a good yield of fermentable sugars, but the presence of high percentage of lignin components may resulted a microbial inhibitors derivative as well orange peel. These presented results matched with those obtained by (Reddy et al 2003, Li et al 2010), which they have reported that, the mango peels released good amounts of fermentable sugars, but the ethanol yield was very low by direct fermentation. On other hand, the bioethanol azeotropic separation process coupled by addition of calcium oxide as drying agent which led finally to achievable $95.5 w t \%$ of pure bioethanol. The distillation of bioethanol formed on fermentation broth will lead to produce azeotropic pure ethanol with $95.5 w t \%$ of final purity, to remove the remaining water, duplicate process applied to reach anhydrous ethanol 97.9 wt \% (Kumar et al 2010). Among several expanding fruits peels fermentation is well known worldwide, other saccharified peels fermentation is extremely rare, but it is already available due to their sugars rich contents (Reddy et al 2003). Until now, the fruit peels fermentation has mainly been covered for only lignin free residuals due to technical and economic considerations, while a lot of fruit peels residue disposed as waste can become low-cost substrates for biofuel production (Banerjee et al 2010, Lee et al 2014). 


\section{Impact of Microbial Synergism on Second Generation Production of Bioethanol from Fruit Peels Wastes}

Table 4. Total saccharified sugars and bioethanol yields from $S$. cerevisiae, $K$. marxianus and its co-fermentation

\begin{tabular}{|c|c|c|c|c|c|c|}
\hline \multirow{2}{*}{$\begin{array}{c}\text { Saccharified } \\
\text { fruits peels }\end{array}$} & \multicolumn{2}{|c|}{ Total enzymatic released sugars g. $^{-\boldsymbol{I}}$} & \multicolumn{3}{|c|}{ Bioethanol g. $^{-\boldsymbol{1}}$ by yeasts strains $^{\text {Pentose }}$} \\
\cline { 2 - 7 } & $\begin{array}{c}\text { Hexose } \\
\text { sugars* }\end{array}$ & $\begin{array}{c}\text { Mixed } \\
\text { sugars* }\end{array}$ & S. cervisiae & $\begin{array}{c}\text { K. } \\
\text { marxianus }\end{array}$ & Co-fermentation \\
\hline Banana & $6.08 \pm 0.6$ & $22.13 \pm 0.2$ & $27.77 \pm 0.7$ & $9.19 \pm 0.2$ & $7.67 \pm 0.7$ & $10.74 \pm 0.8$ \\
\hline Mango & $5.39 \pm 0.4$ & $16.26 \pm 0.7$ & $21.13 \pm 0.3$ & $5.62 \pm 0.5$ & $4.89 \pm 0.5$ & $6.75 \pm 0.7$ \\
\hline Watermelon & $5.26 \pm 0.3$ & $14.47 \pm 0.4$ & $19.56 \pm 0.4$ & $6.07 \pm 0.3$ & $5.36 \pm 0.3$ & $7.35 \pm 0.5$ \\
\hline Orange & $4.08 \pm 0.7$ & $12.05 \pm 0.5$ & $15.97 \pm 0.6$ & $4.45 \pm 0.5$ & $3.89 \pm 0.6$ & $5.31 \pm 0.7$ \\
\hline
\end{tabular}

The values are mean of three replicates \pm standard deviation.

*Pentose, hexose, and mixed sugars (as xylose, glucose and with fructose mixture, respectively).

\section{Conclusion}

Fruit peels wastes annually accumulate in huge amounts, the most discarded fruit peels were selected to determine their added values, the peels of (Orange, Banana, Mango and Watermelon) were effectively fractionated into their beneficial composition of oligosaccharides. The total proteins, starch, pectin, lignin, celluloses, hemicellulose fractions were detected in terms of dry weights percentages for the studied fruit peels. The highest oligosaccharides levels $(62.3 \%)$ were in mango peels but with high levels of fermentation inhibitor lignin content. While banana peels also given high oligosaccharides levels (59.52\%) with the lowest level of lignin. During the degraded fungal enzymes co-production, no antagonistic phenomenon was observed between the studied co-cultivated fugal strains of Aspergillus niger and Phanerochaete chrysosporium, that the co-cultivation can improve extracellular enzyme secretion which resulted an increasing in exo-enzymes activities by 5.9, 8.7 and 81.4 nmol. $\mathrm{min}^{-1} . \mathrm{ml}^{-1}$ for $\beta$-glucosidase, cellulase, and xylanase, respectively. The SDS-PAGE protein profiles achieved that, co-cultivation of the two fungi results in improved the relevant exo-enzymes, the combined fungal profile was contained proteins not observed in the fungus monoculture. On other side, bench top labscale biostatic reactor was carried out for exoenzymes production and saccharification. The total saccharified pentose and hexose fermentable sugars from banana, mango, watermelon, orange peels were $27.77,21.13,19.56$ and 15.97 g. $l^{-1}$, respectively. Two sexual regenerative yeast strains belong to Saccharomyces cerevisiae and Kluyveromyces marxianus contributed for co-production of bioethanol. The productivity of bioethanol increased by more than $18 \%$ as average percentage for all saccharified peels, most substantial yield was from saccharified banana peels by $10.74 \mathrm{~g} \cdot \mathrm{l}^{-1}$. Additional distillation process was applied by adding various drying agents, the adding of calcium oxide increased the purity which leads finally to $97.5 w t \%$ of pure ethanol.

\section{Acknowledgements}

This study was funded by (Applied Research Fund Section - Menoufia University, Egypt) via the financing the project of bioenergy production from agricultural wastes.

Conflicts of Interest: The authors declare no conflict of interest.

\section{References}

Agbor VB, Cicek N, Sparling R, Berlin A, Levin DB (2011) Biomass pretreatment: fundamentals toward application. Biotechnol Adv $29,675-85$.

Aravantinos-Zafiris G, Oreopoulou V, Tzia C, Thomopoulos C (1994) Fibre fraction from orange peel residues after pectin extraction. $L w t$ - Food Sci Technol 27, 468-471. 
Arya A, Shah A, Sadasivan S (2001) Indoor aeromycoflora of Baroda Museum and deterioration of Egyptian mummy. Curr Sci 81, 793-799.

Banerjee S, Mudliar S, Sen R, Giri B, Satpute D, Chakrabarti T, Pandey RA (2010) Commercializing lignocellulosic bioethanol: technology bottlenecks and possible remedies. Biofuel Bioprod Biorefin 4, 77-93.

Berardini N, Knödler M, Schieber A, Carle R (2005) Utilization of mango peels as a source of pectin and polyphenolics. Innov Food Sci Emerg Technol 6, 442-452.

Bradford MM (1976) A rapid and sensitive method for the quantitation of microgram quantities of protein utilizing the principle of protein-dye binding. Anal Biochem 72, 24854.

Camassola M, Dillon AJP (2012) Cellulase determination: Modifications to make the filter paper assay easy, fast, practical and efficient. 1: 125. doi:10.4172/scientificreports. 125

Chen H, Fu X (2016) Industrial technologies for bioethanol production from lignocellulosic biomass. Renew Sust Energ Rev 57, 468-478.

Cutzu R, Bardi L (2017) Production of bioethanol from agricultural wastes using residual thermal energy of a cogeneration plant in the distillation phase. Ferment 3, 24.

de Vries RP, Burgers K, van de Vondervoort PJ, Frisvad JC, Samson RA, Visser J (2004) A new black Aspergillus species, A. vadensis, is a promising host for homologous and heterologous protein production. Appl Environ Microbiol 70, 3954-9.

Demirbas A (2011) Competitive liquid biofuels from biomass. Appl Energ 88,17-28.

Dien BS, Cotta MA, Jeffries TW (2003) Bacteria engineered for fuel ethanol production: current status. Appl Microbiol Biotechnol 63, 258-66.

DuBois M, Gilles KA, Hamilton JK, Rebers PA, Smith F (1956) Colorimetric method for determination of sugars and related substances. Anal chem 28, 350-356.
Fahim S (2017) Production cursors of lipopeptides families by some Bacillus spp. Int J Chem Tech Res 10, 1096-1103.

Farias D, Atala DIP, Maugeri F (2017) Improving bioethanol production by Scheffersomyces stipitis using retentostat extractive fermentation at high xylose concentration. Biochem Eng J 121, 171-180.

Fish WW, Bruton BD, Russo VM (2009) Watermelon juice: a promising feedstock supplement, diluent, and nitrogen supplement for ethanol biofuel production. Biotechnol Biofuels 2,18 .

Gashaw A (2014) Bioethanol Production from Fruit Wastes and Factors Affecting Its Fabrication. Int J Chem Natural Sci 2, 32-140.

Greene ER, Himmel ME, Beckham GT, Tan Z (2015) Glycosylation of Cellulases: Engineering Better Enzymes for Biofuels. Adv Carbohydr Chem Biochem 72, 63-112.

Gupte A, Madamwar D (1997) Solid State Fermentation of Lignocellulosic Waste for Cellulase and $\beta$-Glucosidase Production by Cocultivation of Aspergillus ellipticusand Aspergillus fumigatus. Biotechnol prog 13, 166-169.

Hu HL, van den Brink J, Gruben BS, Wösten HAB, Gu JD, de Vries RP (2011) Improved enzyme production by co-cultivation of Aspergillus niger and Aspergillus oryzae and with other fungi. Int Biodeter Biodegr 65, 248-252.

Kumar S, Singh N, Prasad R (2010) Anhydrous ethanol: A renewable source of energy. Renew Sust Energ Rev 14, 1830-1844.

Lee S, Speight JG, Loyalka SK (2014) Handbook of alternative fuel technologies, $2^{\text {ed }}$ ed, Boca Raton, CRC Press, https://doi.org/10.1201/b17157

Li K, Fu S, Zhan H, Zhan Y, Lucia L (2010) Analysis of the chemical composition and morphological structure of banana pseudostem. BioResources 5, 576-585. 
López-Malo M, Querol A, Guillamon JM (2013) Metabolomic comparison of Saccharomyces cerevisiae and the cryotolerant species $S$. bayanus var. uvarum and S. kudriavzevii during wine fermentation at low temperature. PLoS One 8, e60135.

Makkar HP (2013) Biofuel co-products as livestock feed-opportunities and challenges: processing. AFMA Matrix 22, 23-25.

Martinez D, Larrondo LF, Putnam N, Gelpke MD, Huang K, Chapman J, Helfenbein KG, Ramaiya P, Detter JC, Larimer F, Coutinho PM, Henrissat B, Berka R, Cullen D, Rokhsarm D (2004) Genome sequence of the lignocellulose degrading fungus Phanerochaete chrysosporium strain RP78. Nat Biotechnol 22, 695-700

McClary DO, Nulty WL, Miller GR (1959) Effect of Potassium Versus Sodium in the Sporulation of Saccharomyces. J Bacteriol 78, 3628.

Meijer M, Houbraken JA, Dalhuijsen S, Samson RA, de Vries RP (2011) Growth and hydrolase profiles can be used as characteristics to distinguish Aspergillus niger and other black aspergilli. Stud Mycol 69, 19-30.

Oberoi HS, Vadlani PV, Madl RL, Saida L, Abeykoon JP (2010) Ethanol production from orange peels: two-stage hydrolysis and fermentation studies using optimized parameters through experimental design. J Agric Food Chem 58, 3422-9.

Orozco RS, Hernández PB, Morales GR, Núñez FU, Villafuerte JO, Lugo VL, Ramírez NF, Díaz CEB, Vázquez PC (2014) Characterization of Lignocellulosic Fruit Waste as an Alternative Feedstock for Bioethanol Production. BioResources 9, 1873-1885

Reddy GV, Babu PR, Komaraiah P, Roy KRRM, Kothari IL (2003) Utilization of banana waste for the production of lignolytic and cellulolytic enzymes by solid substrate fermentation using two Pleurotus species (P. ostreatus and P. sajor-caju). Process Biochem 38, 1457-1462.
Rocha-Meneses L, Raud M, Orupõld K, Kikas $\mathrm{T}$ (2019) Potential of bioethanol production waste for methane recovery. Energy 173, 133139.

Saddler JN, Mes-Hartree M (1984) The enzymatic hydrolysis and fermentation of pretreated wood substrates. Biotechnol Adv 2, 161-81.

Sharma DK (2006) Bioprospecting for drug research and functional foods for the prevention of diseases-Role of flavonoids in drug development. JSIR 65, 391-401.

Switzer RC, Merril CR, Shifrin S (1979) A highly sensitive silver stain for detecting proteins and peptides in polyacrylamide gels. Anal Biochem 98, 231-7.

Verma P, Madamwar D (2002) Production of ligninolytic enzymes for dye decolorization by cocultivation of white-rot fungi Pleurotus ostreatus and phanerochaete chrysosporium under solid-state fermentation. Appl Biochem Biotechnol 102-103

Ververis C, Georghiou K, Danielidis D, Hatzinikolaou DG, Santas P, Santas R, Corleti V (2007) Cellulose, hemicelluloses, lignin and ash content of some organic materials and their suitability for use as paper pulp supplements. Bioresour Technol 98, 296-301.

Widmer WW, Narciso JA, Grohmann K, Wilkins MR (2009) Simultaneous saccharification and fermentation of orange processing waste to ethanol using Kluyveromyces marxianus. Biol Eng Trans 2, 17-29.

Yadav KS, Naseeruddin S, Prashanthi GS, Sateesh L, Rao LV (2011) Bioethanol fermentation of concentrated rice straw hydrolysate using co-culture of Saccharomyces cerevisiae and Pichia stipitis. Bioresour Technol 102, 6473-8.

Ziemiński K, Kowalska-Wentel M (2017) Effect of Different Sugar Beet Pulp Pretreatments on Biogas Production Efficiency. Appl Biochem Biotechnol 181, 1211-1227. 

Arab Univ. J. Agric. Sci., Ain Shams Univ., Cairo, Egypt 29(2), 557-571, 2021

Website: http://ajs.journals.ekb.eg

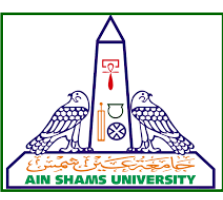

DOI: $10.21608 /$ ajs.2021.75553.1376 